\title{
Systemic lupus erythematosus presenting as polymyalgia rheumatica in the elderly
}

\author{
C W HUTTON AND P J MADDISON
}

From the Royal National Hospital for Rheumatic Diseases, Bath

SUMmaRY Three patients who developed systemic lupus erythematosus (SLE) over the age of 60 are described. All patients presented with a clinical syndrome typical of polymyalgia rheumatica. In two cases there was an underlying myositis.

Key word: myositis.

Variation in the clinical presentation is a striking characteristic of SLE. This depends on the spectrum of organ involvement and fluctuation of disease activity. Its features blur with those of other connective tissue diseases, so that diagnosis may be difficult. SLE in the elderly is particularly variable in its clinical pattern and may differ from the disease seen in younger patients. ${ }^{1}$ Its presentation may therefore be very atypical. Whether this is because it is a different disease process in the elderly or a modification by age of the underlying disease is unknown. Recognition of unusual presentations of connective tissue diseases in the elderly is important to allow appropriate effective therapy. We describe three cases of SLE presenting with a polymyalgia rheumatica-like syndrome, two of whom were found to have an underlying myositis.

\section{Case reports}

\section{CASE 1}

A 76 year old Caucasian man presented with proximal muscle pain and stiffness associated with marked weight loss which had developed over four months. He had had mild Raynaud's disease two years previously. Examination was unremarkable, and in particular there was no evidence of muscle weakness. Laboratory investigations showed a raised plasma viscosity of 1.94 (normal range 1.54-1.72) and a normochromic normocytic anaemia. Serology showed a weakly positive antinuclear antibody (ANA) titre (40 IU) but normal DNA binding. The serum creatine phosphokinase

Accepted for publication 14 February 1986.

Correspondence to Dr C W Hutton, Royal National Hospital for Rheumatic Diseases, Upper Borough Walls, Bath BA1 1RL.
(CPK) and transaminase levels were normal. The diagnosis of polymyalgia rheumatica was made, and he was treated with prednisolone $15 \mathrm{mg}$ a day initially, which was subsequently reduced to a maintenance dose of $5 \mathrm{mg}$ a day. Despite initial dramatic improvement in his muscle stiffness and pain he became insidiously weaker and was readmitted two years later with profound muscle weakness and wasting, predominantly affecting the proximal and bulbar muscles. Laboratory investigations showed a viscosity of 1.92 . Haemoglobin was 126 $\mathrm{g} / \mathrm{l}$. He had a polymorphonuclear leucocytosis of $19.9 \times 10^{9} / 1$ (normal range $4-11 \times 10^{9} / 1$ ) but a lymphopenia of $0.6 \times 10^{9} / 1$ (normal range $1.5-4.0 \times 10^{9} / 1$ ) $\mathrm{C}$ reactive protein was raised at $0 \cdot 16 \mathrm{~g} / \mathrm{l}$ (normal $<0.01 \mathrm{~g} / \mathrm{l})$. Creatine phosphokinase and transaminases were normal. Serology showed a raised ANA titre of $640 \mathrm{IU}$, DNA binding of $30 \%$ (normal range $<20 \%$ ), but no precipitating antibodies to soluble non-histone antigens were detected. Raised anticholinergic receptor antibody titres $(46 \cdot 7$, normal $<2)$ were noted, but both neostigmine and pyridostigmine stimulation tests were negative. Muscle biopsy showed marked atrophy of all fibre types, with replacement fibrosis and a mild inflammatory mononuclear cell infiltrate. A skin biopsy specimen from uninvolved skin from the extensor aspect of the forearm showed granular deposition of IgM and C3 at the dermatoepidermal junction.

A diagnosis of myositis complicating SLE was made. Prednisolone was increased to $30 \mathrm{mg}$ a day and methotrexate added. After a single $5 \mathrm{mg}$ dose of methotrexate he developed an aplastic anaemia which was complicated by septicaemia, and he died. Postmortem examination confirmed the extensive muscle involvement (Fig. 1). 


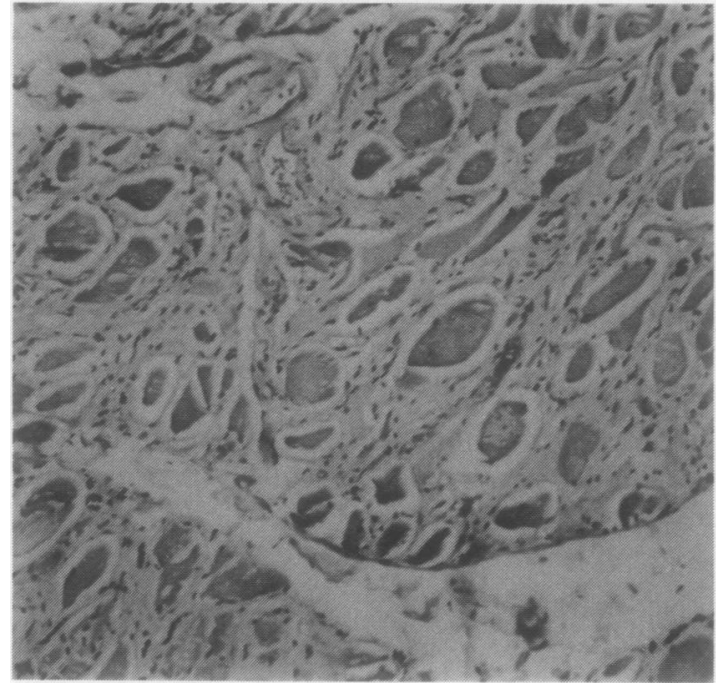

Fig. 1 Striated muscle specimen taken after death showing extensive fibrosis and muscle fibre atrophy. (Haematoxylin and eosin).

\section{CASE 2}

A 62 year old Caucasian woman developed severe pain and stiffness in the upper and lower limb girdle overnight. A diagnosis of polymyalgia rheumatica was made, and the symptoms resolved over one month with treatment with flurbiprofen $50 \mathrm{mg}$ three times a day. Three months later the symptoms recurred, now associated with pain in the small muscles of the hand, dyspnoea, and pleuritic chest pain. On examination she had mild proximal muscle weakness but no wasting, synovitis of the second and third metacarpophalangeal joints, proximal interphalangeal joints, both wrists, and right knee, and bilateral coarse crepitations at both lung bases. Investigation showed a raised viscosity of 1.87 , and normochromic normocytic anaemia, a leucopenia with a white cell count of $2.4 \times 10^{9} / 1$, of which $0.4 \times 10^{9} / 1$ were lymphocytes. Serology showed a positive ANA titre (164 IU), precipitating antibodies to the cytoplasmic ribonuclear protein, Ro (SSA), but DNA binding was normal. Schirmer's test was positive. Chest $x$ ray showed pulmonary fibrosis, and pulmonary function test demonstrated a diminished transfer factor KCO of 1.4 (expected value 1.65). The serum $C P K$ and transaminase levels were normal, but an electromyogram showed polyphasic potentials, and a muscle biopsy confirmed an interstitial inflammatory infiltrate diagnosing an underlying myositis (Fig 2). There was no evidence of renal, neurological, or skin disease. The diagnosis of myositis complicating another connective tissue disease, possibly systemic lupuson erythematosus, was made. She was treated with $\overrightarrow{\vec{F}}$ prednisolone $30 \mathrm{mg}$ a day, with immediate clinical $\stackrel{\text { के }}{\circ}$ improvement.

CASE 3

A 73 year old Caucasian woman presented with sudden onset of severe muscle stiffness, myalgia, and weight loss. She had become increasingly $\vec{\circ}$ dyspnoeic and had developed Raynaud's phenomenon in association with gritty eyes and marked hair $\vec{\omega}$ loss over the previous year. Ten years previously she $\frac{\Omega}{9}$ had had a similar illness, diagnosed as polymyalgia rheumatica and treated for a year with predniso- $\mathrm{c}$ lone. This had gone into remission but recurred fiveco years previously and was then associated with a positive ANA (titre 1 in 40), in addition to a high erythrocyte sedimentation rate and a normochromic음 normocytic anaemia. Again she had responded well to corticosteroid therapy.

On admission she had diffuse alopecia, basa pulmonary crepitations, but there was no evidence? of muscle weakness, wasting, or skin rash. Laboratory $\overrightarrow{0}$ investigation showed a raised plasma viscosity of 1.95 with a normochromic normocytic anaemia.CPK and transaminase levels were normal. Hers ANA titre was $\mathbf{4 0} \mathrm{IU}$, with a deoxyribonucleic acide binding of $30 \%$. She had precipitating antibodies tom Ro(SSA) and $\mathrm{La}(\mathrm{SSB})$. A cold test confirmed sheep had Raynaud's disease, and Schirmer's test was positive. Salivary gland biopsy confirmed Sjögren's syndrome. Chest $x$ ray showed diffuse pulmonary

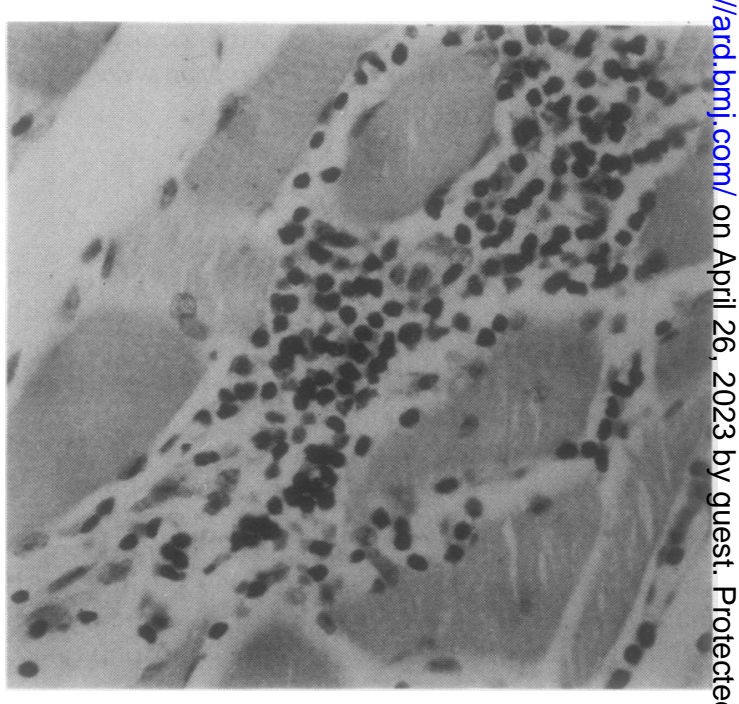

Fig. 2 Striated muscle biopsy specimen showing cellular infiltration and muscle degeneration ( $H$ and $E$ ). 
infiltration consistent with fibrosis. The gallium scan was negative, bronchial lavage was hypocellular, and pulmonary function test showed a diminished $\mathrm{KCO}$ of 0.4 (predicted value 1.56 ).

She was treated with prednisolone $30 \mathrm{mg}$ a day, which produced a dramatic improvement in her symptoms and enabled her to be maintained on a level of $5 \mathrm{mg}$ a day. She has remained well for 18 months.

\section{Discussion}

These three cases illustrate how polymyalgia rheumatica can be the presenting feature of a connective tissue disease and in two patients showed how this can mask an underlying myositis.

Systemic lupus erythematosus is increasingly recognised as presenting in the elderly. A number of studies show that between 10 and $20 \%$ of patients present over the age of $55 .^{1-7}$ These studies have also recognised that the clinical disease pattern is different in the elderly than in younger patients. Its onset is more insidious, and there is less cutaneous, renal, and central nervous system disease. Lung disease is often very prominent, but its course appears to be more benign. This pattern of disease overlaps Sjögren's syndrome. Indeed, although one case we describe fully satisfies the revised American Rheumatism Association diagnostic criteria for systemic lupus erythematosus ${ }^{\circ}$ and the other two have characteristic clinical and serological markers, they do show features of Sjögren's syndrome. Two patients had keratoconjunctivitis sicca and antibodies to the cytoplasmic protein Ro(SSA). These antibodies are found in systemic lupus erythematosus in a frequency varing between 25 and $40 \%^{9-11}$ and also in up to $70 \%$ of patients with primary Sjögren's syndrome $\mathrm{e}^{12}{ }^{13}$ but are rare in other conditions.

Muscle disease is common in systemic lupus erythematosus. ${ }^{14}$ In myositis, myopathy and myaesthenic syndrome have been described. Foad et al first described five elderly patients in whom a polymyalgia rheumatica-like syndrome had been the presentation of systemic lupus erythematosus. ${ }^{1}$ In none of those patients, however, was there underlying muscle disease. Myopathy presenting with marked weaknesses also has been described as a presentation of elderly patients with Sjögren's syndrome, ${ }^{15}$ but polymyalgia rheumatica has not been described as a presenting feature of this myopathy. In the three cases we describe all present with a polymyalgia rheumatica syndrome. In one case there was no evidence of underlying muscle disease, but one subsequently developed a severe myositis, which was possibly present earlier but masked by the features of polymyalgia rheumatica.
The third had evidence of myositis at the time when she presented with clinical syndrome of polymyalgia rheumatica. In one case described here these antibodies were present, but the failure of the patient to respond to either neostigmine or pyridostigmine testing makes it unlikely they had any clinical significance.

Polymyalgia rheumatica is typically associated with giant cell arteritis ${ }^{16}$ and may be related to other connective tissue diseases, in particular rheumatoid arthritis, but this relationship remains uncertain. ${ }^{17}$ It has been described in association with a positive antinuclear antibody titre but no other clinical evidence of SLE. ${ }^{18}$ The cases we describe, together with those described by Foad, suggest that the syndrome of polymyalgia rheumatica may also be associated with the development of systemic lupus erythematosus. Two of the cases show that a polymyalgia rheumatica-like syndrome may be obscuring an underlying myositis. So with polymyalgia rheumatica, particularly if there are any features of a connective tissue disorder, or a poor response to treatment, the possibility of systemic lupus erythematosus should be considered. It is particularly important because an unrecognised underlying myositis may develop which will require appropriate steroid and immunosuppressive therapy.

\section{References}

1 Foad B S I, Sheon R P, Kirsner A B. Systemic lupus erythematosus in the elderly. Arch Intern Med 1972; 130: 743-6.

2 Dubois E L. Lupus erythematosus. New York: McGraw-Hill, 1966.

3 Harvey A M, Shulman L E, Tumulty A, et al. Systemic lupus erythematosus: review of the literature and clinical analysis of 138 cases. Medicine (Baltimore) 1954; 33: 291-437.

4 Kellum R E, Haserick J R. Systemic lupus erythematosus: a statistical evaluation of mortality based on a consecutive series of 299 patients. Arch Intern Med 1964; 113: 200-7.

5 Urowitz M B, Stevens M B, Shulman L E. The influence of age on the clinical pattern of systemic lupus erythematosus. Arthritis Rheum 1967; 10: 319-20.

6 Catoggio L J, Skinner R P, Smith G, Maddison P J. Systemic lupus erythematosus in the elderly: clinical and serological characterisitcs. J Rheumatol 1984; 11: 175-81.

7 Ballou S P, Khan M A, Kushner I. Clinical features of systemic lupus erythematosus. Differences related to race and age of onset. Arthritis Rheum 1982; 25: 55-60.

8 Tan E G M, Cohen A S, James F F, et al. The 1982 revised criteria for the classification of systemic lupus erythematosus. Arthritis Rheum 1982; 25: 1271-7.

9 Maddison P J, Mogavero H, Provost T T, Reichlin M. The clinical significance of autoantibodies to a soluble cytoplasmic antigen in systemic lupus erythematosus and other connective tissue disorders. J Rheumatol 1979; 6: 189-95.

10 Maddison P J, Catoggio L J, Skinner R P. Antibodies to Ro(SSA): clinical spectrum in an English rheumatic disease population. $X V$ Int Congress Rheumatol, Paris. June 1981, Abstr No 620. 
11 Scopelitis E, Biundo J J, Alspaugh M A. Anti SSA antibody and other antinuclear antibodies in systemic lupus erythematosus. Arthritis Rheum 1980; 23: 287-92.

12 Alspaugh M A, Talal N, Tan E M. Differentiation and characterization of autoantibodies and other antigens in Sjögren's syndrome. Arthritis Rheum 1976; 19: 216-22.

13 Martinez-Lavin M, Vaughan J M. Tan E M. Autoantibodies and the spectrum of Sjögren's syndrome. Ann Intern Med 1979; 91: $185-90$.

14 Isenberg D A. Snaith M L. Muscle disease in systemic lupus erythematosus - a study of its nature, frequency and cause. $J$ Rheumatol 1981; 8: 917-24.
15 Silberberg D H. Drachman D A. Late-life myopathy occurring with Sjögren's syndrome. Arch Neurol 1962; 6: 428-38.

16 Wilske K R. Healey L A. Polymyalgia rheumatica: a manifestation of systemic giant cell arteritis. Ann Intern Med 1967; 66: 77-86.

17 Healey L A. Polymyalgia rheumatica and the American Rheumatism Association criteria for rheumatoid arthritis. Arthritis Rheum 1983; 26: 1417-8.

18 Healey L A, Parker F. Wilske K R. Polymyalgia rheumatica and giant cell arteritis. Arthritis Rheum 1971: 14: 138-41. 